\title{
To the quality of project documentation
}

\author{
Martin Tuháček ${ }^{1, *}$ and Pavel Svoboda ${ }^{1}$ \\ ${ }^{1}$ CTU in Prague, Faculty of Civil Engineering, Thákurova 7, 16629 Praha 6, Czech Republic
}

\begin{abstract}
The article deals with the topic of control of the project documentation, the quality of the project documentation and its influence on the final quality of the realized product. The aim is to create tools for monitoring of defects and their analysis. As part of improving the control of project documentation, I am introducing a system of classification of complained defects. These defects are then focused on expert analysis. Based on its evaluation, I apply the knowledge gained to the project documentation control. My goal is to create a system, that will prevent the recurrent occurrence of identical claimed defects. By eliminating of claimed defects it is possible to achieve considerable financial savings within building companies.
\end{abstract}

\section{Building defects and project documentation}

There are a variety of reasons for building defects and they are not easy to identify. If we want to prevent defects it is crucial to identify their cause. Therefore, we need to implement defect categorization. In the article I review the checking of project documentation in interaction with the database of claimed defects. With defect categorization we can further analyse the collected data and use the information to prevent future defects and improve the economic results of implemented construction projects.

Poor project documentation often causes defects. This article introduces us to the tools for analysing identified defects. The information collected during the analysis is then used for better control of the project documentation.

The idea behind this principle is to never stop improving the overall quality, which consequently lowers the number of identified defects. Last but not least, after implementing these tools, there are also financial advantages.

\section{Types of building defects}

Building defects are found on various structural parts of buildings. To analyse identified defects requires categorization. Sorting of claimed defects is the most effective way to identify the most risky defects. With categorization we can determine higher risk defect groups and specific defects with higher occurrence. All this will be described in the following text.

\footnotetext{
*Corresponding author: Martin.Tuhacek@metrostav.cz
} 


\subsection{Types of defects}

When identifying the defect, it is important to monitor what kind of defect it is in which type of construction the defect has occurred. It is also important to identify the correct cause of the fault and, last but not least, to which parts of the building a defect has occurred.

\subsubsection{Types of defects}

There are two basic groups based on the type of defect:

- Common defects

- Accidents

These two groups have different requirements for resolving defects. The first group are common defects. These defects can be removed in a simple way. It is mostly a replacement or repair of a defective part. The second group are accidents. These are defects of a larger scale. Removal of these defects is not easy. Their removal requires more intervention in the work, not just repairing a defective part.

\subsubsection{Kinds of construction}

This breakdown distinguishes the kinds of objects where the defects occurred. Within large building companies, this allows us to identify the kinds of construction, which has the largest number issues.

For this purpose, buildings can be divided into:

- Public buildings.

- Residential construction.

- Industrial construction.

- Transportation construction.

- Underground construction.

- Engineering construction.

- Other construction.

\subsubsection{Cause of defects}

The cause of defects can be separated into two areas. The first are caused due to the project documentation. This is where we classify assignment defects, documentation defects in the area of statics and in the area of coordination. Coordination of project documentation, its parts, and coordination of all participants involved in design process is very complex [1] and may be supported by implementation of common data environment [2].

Also, there is a high factor of possible human failure, which may cause defects due to low level of clarity [3]. Widely problematics of information insufficiency in construction project is described in [4].

The second are caused during the construction process itself, for example not following correct technical procedures.

Defects of from both groups are included in the IPV classification that identifies defects with the highest risk. The findings are included in the project documentation checks or inspections on the construction site. To simplify the process of controlling project documentation and on-site inspections, control forms are created.

There are tools for project coordination such as process modelling standards, e.g. [5], which may help to coordinate the project documentation and construction process itself and methods for definition of project requirements and scope [6]. 


\subsubsection{Defect specifications according to structural components, profession}

Separating defects according to the specific structural components of where the defects occurred, assists us with identifying the components that are most prone to defects.

We can consequently give more attention to the project documentation for the parts of construction with the highest rate of defects. Here are a few groups used for this activity:

- Brick structures.

- Roads.

- Facade.

- Windows.

- Floors.

- Waterproof coating.

- Heating.

- Electricity and more

\section{Linking defect monitorization with revision of project documentation}

Revising project documentation is quite difficult, as it requires a certain level of knowledge of what is being documented as well as the various revision changes of the document. This can be divided into two parts.

The first is quite simple and is based on the requirements dictated by building law, which tells us what each level of project documentation should include. Specialization requirements for the person performing the revisions are not high.

The second level of revision requires a much higher level of knowledge of the part of the project documentation because the main focus is on technical accuracy. For simplification of the second level revision of the analysis of identified defects is described bellow. Based on the analysis of identified defects the tools are developed to make it easier to revision the project documentation.

\subsection{Revisions of project documentation and constant quality improvement}

As stated, revising project documentation based on the analysis of identified defects assists with continually improving quality. The PDCA acronym is well known in the area of quality monitoring. This stands for Plan, Do, Check, Act. [7]

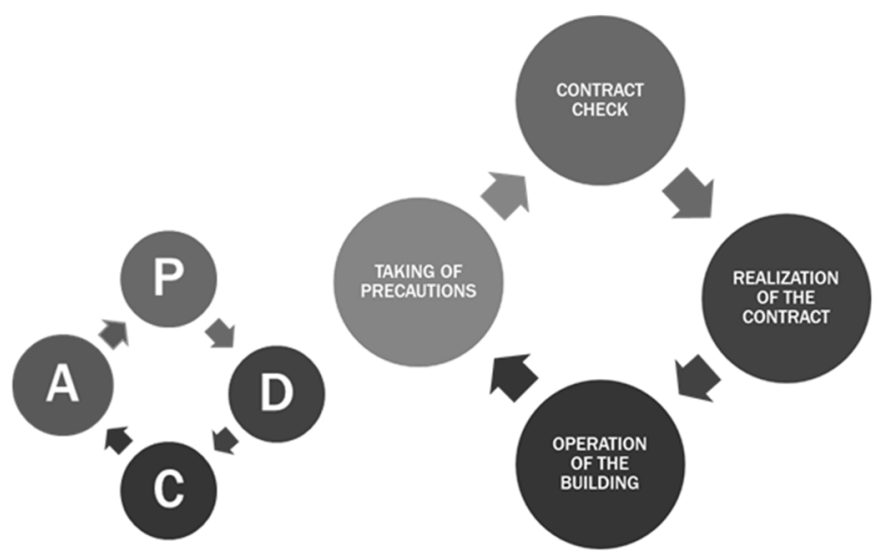

Fig. 1. a) PDCA diagram - universal [3]; b) Modified PDCA diagram for the purpose of work 


\subsection{Tools for analysing identified defects}

FMEA was selected as the proper method for analysis of identified defects. FMEA stands for Failure Mode and Effect Analysis. Originally developed for NASA, this method has been widely used in the auto industry since the 80 s and is still in use today.

"The FMEA method is a verbally-numerical and quality-quantitative rating method used for evaluation of reliability of planned projects in risk analyses. This method systematically reveals possible defects and their aftermath." [8]

FMEA uses so called risk priority numbers - RPN. The following formula provides universal regulation for RPN [8].

$$
R P N=R_{t 1} E x R_{t 2} E x R_{t 3} E x \ldots \times R_{t m} E
$$

$\mathrm{RtjE}$ are expert ratings and its product is the RPN value (risk priority number). It is up to a decision of the expert team that is performing the analyses how many expert ratings they choose. For the purpose of my work, I focused the RPN on IPV. The IPV marks the index priority of defect. For simplicity the rating can be perceived as assigning negative points. The higher the rating the higher risk.

I adjusted the universal regulation (1) for the purpose of my work to the following formula.

$$
I P V=S_{v} \times R_{m}
$$

$\mathrm{S}_{\mathrm{v}}$ - the cost of removing the defect

$\mathrm{R}_{\mathrm{m}}$ - difficulty in removing the defect

Table 1. The cost of removing the defect $-\mathrm{S}_{\mathrm{v}}$

\begin{tabular}{|c|c|}
\hline $\begin{array}{c}\text { The cost of removing } \\
\text { the defect (CZK) }\end{array}$ & Sv \\
\hline $0-20.000$ & 1 \\
\hline $20.000-40.000$ & 2 \\
\hline $40.000-60.000$ & 3 \\
\hline$>60.000$ & 4 \\
\hline
\end{tabular}

Table 2. Difficulty in removing the defect $-\mathrm{R}_{\mathrm{m}}$

\begin{tabular}{|c|c|}
\hline $\begin{array}{c}\text { Difficulty in } \\
\text { removing the defect }\end{array}$ & Rm \\
\hline $\begin{array}{c}\text { Easy (not time } \\
\text { consuming) }\end{array}$ & 1 \\
\hline $\begin{array}{c}\text { Easy (but time } \\
\text { consuming) }\end{array}$ & 2 \\
\hline $\begin{array}{c}\text { Difficult to remove } \\
\text { (time and financial } \\
\text { side) }\end{array}$ & 3 \\
\hline Practically impossible & 4 \\
\hline
\end{tabular}




\subsection{Analysis of the identified defects and its evaluation}

Thanks to the procedure described above every defect obtains the IPV evaluation. The identified defects are sorted according to the type of construction. This approach also shows us what types of construction are prone to more serious defects. For the purpose of my analyses I introduce the IPV. This type of sorting highlights high risk defect groups in the project documentation. The following formula provides total defect priority index - IPV tot [9].

$$
I P V_{\text {tot }}=\sum_{K=1}^{K=M} I P V_{K}
$$

\section{Applying knowledge for revision of project documentation}

Major construction companies currently implement the above described procedures for defect analysis of identified defects.

Applications for the management and management of complained defects will serve for a more transparent solution of the defects complained of and the confusion of all documents in one place.

The analysis provides tools that serve as check points for revisions to project documentation. Namely, check-lists, check forms, risk technology database, database of risky materials.

\section{Conclusion}

The identified defects are a significant burden on the budgets of building organizations. Early control of the upcoming building projects can eliminate future defects. The results of analyses identified the partial risks associated with the concept of the problem and the finding of effective preventive procedures to eliminate defects, i.e. to increase the resistance of the structure before the risks are realized. [10] Due to the short time frame in revising project documentation, using this time effectively is critical. As mentioned, the analysis gathered from past defects can make the revisions more efficient. Though the defects cannot be completely eliminated they can be significantly lowered using these types of procedures.

Eliminating the occurrence of complaints can significantly accentuate significant financial savings in talking about future recollections.

\section{References}

1. K. Prušková, J. Kaiser, World Multidisciplinary Civil Engineering-Architecture-Urban Planning Symposium 2018, (to be published)

2. J. Rádl, J. Kaiser, World Multidisciplinary Civil Engineering-Architecture-Urban Planning Symposium 2018, (to be published)

3. K. Prušková, MATEC Web of Conferences, 146, 01009 (2017)

4. J. Rádl, J. Kaiser, Proceedings of the 30th International Business Information Management Association Conference, IBIMA 2017 - Vision 2020: Sustainable Economic development, Innovation Management, and Global Growth, 2017-January, 5059-5070, (2017) 
5. J. Myslín, J. Kaiser, Proceedings of the 29th International Business Information Management Association Conference - Education Excellence and Innovation Management through Vision 2020: From Regional Development Sustainability to Global Economic Growth, 3598-3606, (2017)

6. J. Myslín, J. Kaiser, Proceedings of the 29th International Business Information Management Association Conference - Education Excellence and Innovation Management through Vision 2020: From Regional Development Sustainability to Global Economic Growth, 4002-4013, (2017)

7. J. Plura, Planning and continuous improvement of quality, 244 (Computer Press, 2001)

8. J. Fotr, I. Souček, Investment decision-making and project management: how to prepare, finance and evaluate projects, manage their risk and create a portfolio of projects, 408 (Grada, 2011)

9. Tichý, Milík, Valjentová, Expert and Expert Judgments (in Czech: Experti a expertizy) (Linde, 2011)

10. J. Synek, M. Popenková, MATEC Web of Conferences, 146, 01005 (2018) 